\title{
MULTISPECTRAL DIGITAL IMAGE MAPPING OF ANTARCTIC ICE FEATURES
}

\author{
by \\ Charles Swithinbank \\ (British Antarctic Survey, Natural Environment Research Council, High Cross,
} Madingley Road, Cambridge CB3 OET, UK)

and

Baerbel K. Lucchitta

(U.S. Geological Survey, Branch of Astrogeology, 2255 North Gemini Drive, Flagstaff, Arizona 86001, U.S.A.)

\begin{abstract}
Landsat multispectral images of the Antarctic ice sheet have been digitally enhanced by the US Geological Survey to show ice surface features not seen in earlier photographic products of the same scenes. Now for the first time it is worthwhile to prepare image maps at scales of up to 1:250000 of ice sheet areas even where no nunataks are visible. Derivatives of the data can be stretched to bring out glaciologically significant features in smooth areas that traditionally have been described as featureless. Over large tracts of the ice sheet, the direction of ice flow can be revealed as clearly as it is by the medial moraines of an Alpine glacier system. Ice streams, ice divides, ice rises, ice rumples, grounding lines, crevasses, and rifts are seen where none had been identified before. In the same way that Seasat altimetry of the surface of the ocean has much to tell about the bed of the ocean, Landsat has much to tell about the bed of the ice. Not only major structural features but also many details of the sub-glacial landscape are unmasked by their subtle reflection on the ice sheet surface. Ground control on ice sheets can be obtained by Doppler satellite observations tied to image-identifiable surface features. Because of ice movement, the standard of geodetic control can never approach that of conventional surveys based on rock stations. But the precise standards of conventional surveys are unnecessary for ice sheet maps.
\end{abstract}

\section{INTRODUCTION}

Of the maps published with the proceedings of the first Symposium on Glacier Mapping (Gunning 1966), the majority were at scales larger than $1: 25000$ and none was at a scale smaller than 1:50000. In contrast, polar ice sheet mapping is likely to progress from small towards larger scales. Only 20 per cent of Antarctica is mapped at scales of 1:250000 or larger. Strange as it may seem, the far side of the Moon is better mapped than most of Antarctica. Ice sheets on Earth cover about $15.6 \times 10^{6} \mathrm{~km}^{2}$, so rather small scales will have to be used if we are to complete the first generation of maps before the end of the century. Some early ice sheet maps are planned for 1:1000000 scale and in this paper we do not consider scales larger than 1:250 000 .

Ninety nine per cent of Antarctica is ice-covered, ye ninety nine per cent of all conventional or satellite image maps published contain rock outcrops. This paradox is explained by the problem of ground control, which is limited to these same outcrops. Topographic surveyors abhor moving ice and so concentrate their talents on rock outcrops. But glaciologists need maps in order to understand ice sheet dynamics and should encourage surveyors to help them. With the launch of Landsat 1 in 1972, satellite imagery opened the door to the economical production of planimetric ice sheet image maps of sufficient accuracy to be useful. The first generation of image maps used photographic products in which the grey scale was directly proportional to the reflectivity of surface features in the spectral band being sampled. In the majority of images, rock outcrops and the sea were reproduced as undifferentiated black, while snow appeared as a featureless grey. In spite of these very serious limitations, the information conveyed was so valuable that image maps were published in USA, UK, Australia, Japan, New Zealand, Norway, and South Africa. Some image maps have been prepared as base maps for geological mapping. The total number of sheets now published is approaching 100 . In addition, many uncontrolled Landsat images have been included in other publications. However, there is still a tendency to cling to nunataks for control. The first 1:1 000000 image map to venture beyond all nunataks was Berkner Island, Antarctica, 1:1 000 000, sheet ST21-24 (US Geological Survey, Open-File Report 84-306, 1984). It was partly controlled by geodetic Doppler satellite observations, tied to ice features.

The second generation of Antarctic image maps will probably be made from digitally-enhanced multispectral images (Lucchitta and others, 1985). The third generation should consist of fully-controlled image maps made from stereo-pairs derived from tilting sensors carried by SPOT or other similarly-equipped satellites.

\section{DIGITAL ENHANCEMENT}

About 170 computer-compatible tapes (CCTs) from Landsat Multispectral Scanner (MSS) images have been acquired by the US Geological Survey in order to produce planimetric, false-colour composite-image maps in polar stereographic projections. The CCTs cover coastal and near-coastal areas of Victoria Land, West Antarctica, and the Antarctic Peninsula, and selected areas in the Ellsworth Mountains, Shackleton Range, Queen Maud Land, and the Amery Ice Shelf. Landsat coverage extends only to about latitude $81^{\circ} \mathrm{S}$, so large parts of the Transantarctic Mountains are not available for analysis.

The tapes were subjected to routine image processing such as radiometric corrections, noise and striping removal, and geometric correction of distortions introduced by the MSS scanner. Further processing included haze removal and image enhancement, in which linear stretches were applied to individual MSS bands after inspection of the grey-value (digital-number) histograms. Images of exceptionally poor quality underwent a second round of clean-up procedures. Special filters, which emphasize small features or sharpen edges significantly, were used to enhance detail in some images. Such techniques help to bring out subtle flow lines and fine structures in the rolling ice-sheet surface.

A particular problem in Antarctic Landsat MSS snow scenes is the saturation of bands $4(0.5$ to $0.6 \mu \mathrm{m}$, green $)$, band $5(0.6$ to $0.7 \mu \mathrm{m}$, red), and $6(0.7$ to $0.8 \mu \mathrm{m}$, nearinfrared). A statistical study showed that saturation increases 


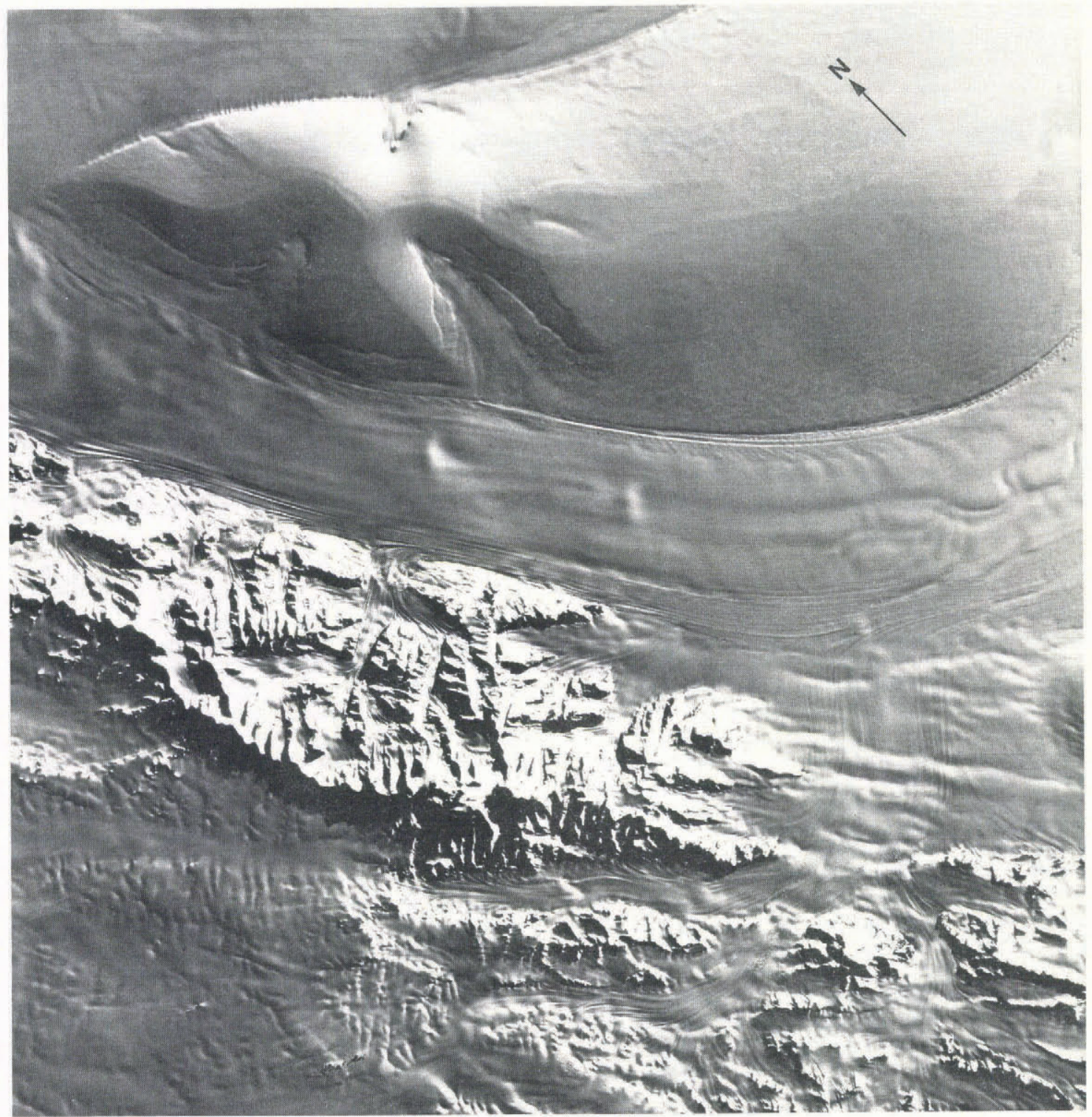

Fig.1. Landsat 1 digitally-enhanced composite image of the Sentinel Range, Ellsworth Mountains, and Rutford Ice Stream, 3 February 1974 (No. 1560-11492, bands 4, 5, and 7; Path 225, Row 117). NASA image courtesy of Flagstaff (Arizona) Image Processing Facility, US Geological Survey.

with increasing sun angle. A technique was developed to restore saturated bands 4 and 5 from unsaturated values in band 6 and band 7 (0.8 to $1.1 \mu \mathrm{m}$, near-infrared). During this restoration, images were scanned for unsaturated snow and ice areas and statistical relations were established for the band ratios $4 / 7,5 / 7$, and $6 / 7$. From these ratios, values of bands 4 and 5 were predicted as functions of the $6 / 7$ ratios and the intensity of band 7. A second pass through the data applied these functional relations to saturated areas. For images having insufficient areas of unsaturated snow and ice, the functional relation from other less saturated images was applied.

The enhanced images used in this paper are not saturated. The scene of the Rutford Ice Stream (Fig.1) underwent a linear stretch in which dark and light areas were stretched differently to bring out maximum definition in snow and ice. The scene of the Ronne Ice Shelf (Fig.4) underwent routine enhancement with special stretches to optimize the detail in the image.

\section{INTERPRETATION}

Figures 1 and 2 offer a comparison between a digitally-enhanced multispectral image and a standard band 7 print of the Rutford Ice Stream. A colour reproduction of the enhanced image would highlight further detail. Earlier, eight band 7 scenes were used for making a first-generation

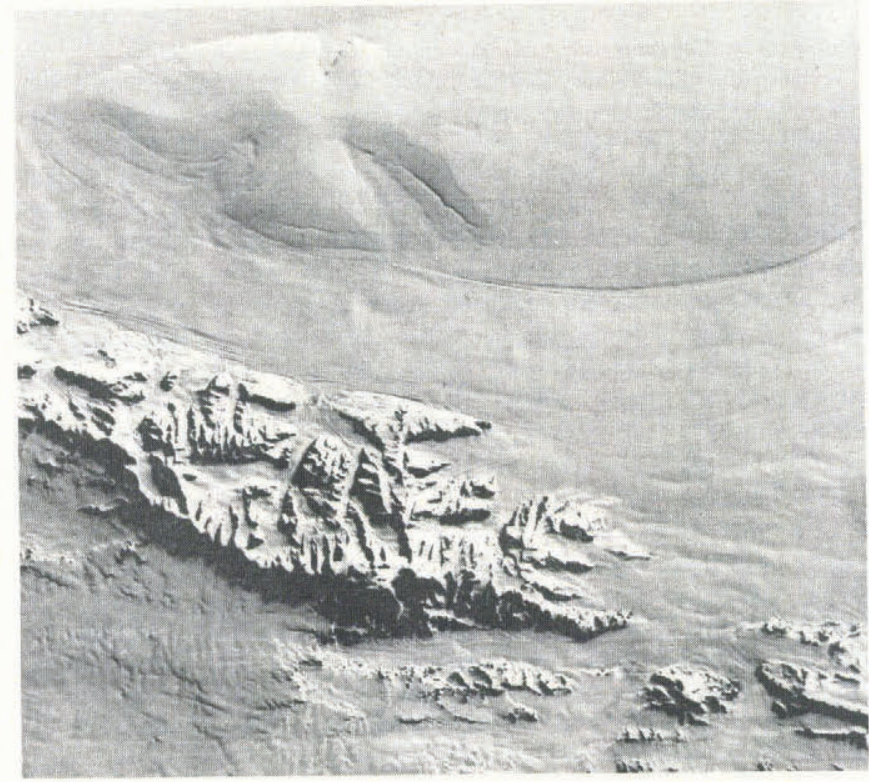

Fig.2. Standard print of the same scene (No. 1560-11492, band 7) without enhancement. From print supplied by EROS Data Center. 
image map of this area (Ellsworth Mountains Antarctica Satellite Image Map 1:500 000. Reston, US Geological Survey, 1976). Depiction of the mountain range is little improved in our multispectral print because it was enhanced for glaciological purposes, but there is a dramatic improvement in the ice surface detail.

Figure 3 shows place names used to discuss the area, and ice thicknesses to help with the interpretation of surface features. Nimitz and Minnesota glaciers drain ice from the plateau to the west of the mountains; both flow in deeply-incised channels. The $1380 \mathrm{~m}$ sounding at the head of Nimitz Glacier coincides with clear surface indications of a sub-glacial trench that can be followed in other images for a further $100 \mathrm{~km}$ north-north-westwards. The $1230 \mathrm{~m}$ sounding on Minnesota Glacier indicates another trench that can be followed upstream for a further $150 \mathrm{~km}$. The glacier appears to have jumped a series of structurally controlled divides on its winding path from west to east through the mountain ranges. On the eastern side of the mountains, ice flow features reveal the direction of ice movement everywhere except on Fletcher Promontory. Although on Rutford Ice Stream there is nothing to indicate the position of the grounding line as determined on the ground by Stephenson and Doake (1982), we believe that the long wavelength surface features towards the left of the image are characteristic of a sliding glacier, whereas the non-linear features towards the right are characteristic of a mainly floating glacier. While a freely-floating glacier generally shows only longitudinal or transverse flow features, the sinuous depressions on the right suggest that here the ice is sliding over shoals and being partially deflected by them. A British Antarctic Survey party that traversed the area in January 1985 saw no crevasses but estimated that the surface relief was of the order of $10 \mathrm{~m}$ (personal communication from Andrew Smith).

Another feature shown clearly for the first time is the apparent double summit ridge of Fletcher Promontory. While well-defined ridges are commonly seen in Landsat images of Antarctic ice rises, even careful optical levelling has so far failed to demonstrate their existence (Martin and Sanderson 1980). Martin (1976) used a sand-model analogue to simulate ridge formation but nobody has yet explained or even demonstrated the existence of the double ridge seen here.

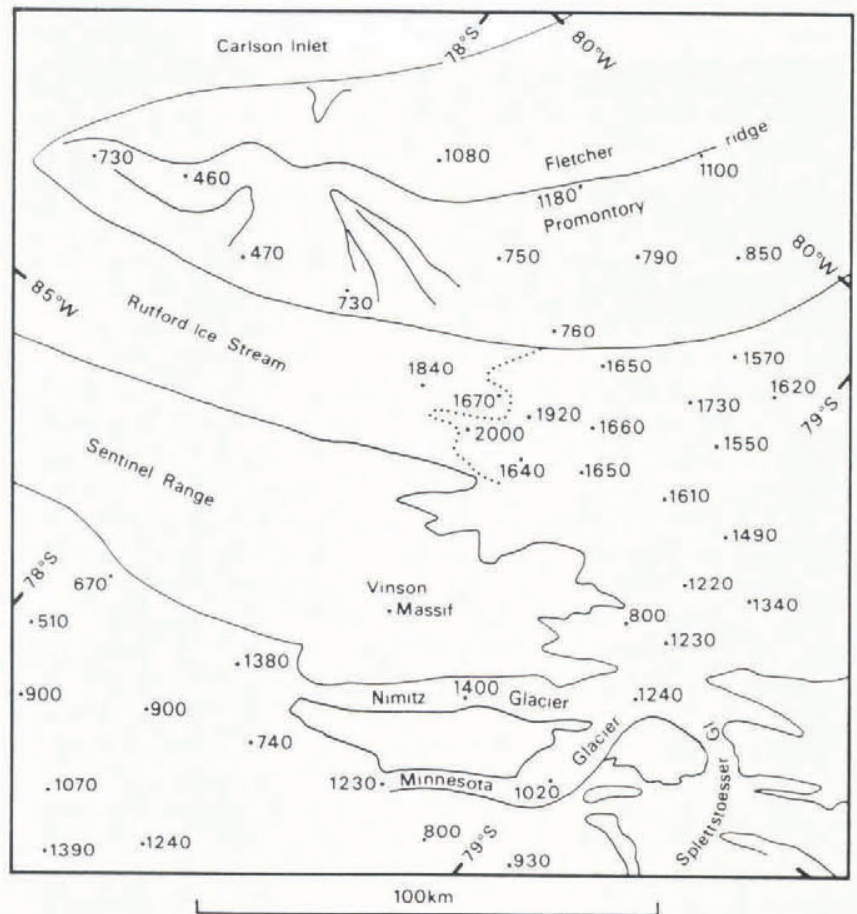

Fig.3. Sketch map of features shown in Fig.1. Spot soundings give ice thickness (in metres) from airborne and surface radio-echo sounding by British Antarctic Survey (unpublished). The dotted line represents the inferred position of the grounding line extrapolated from Stephenson and Doake (1982).
Figures 4 and 5 present a digitally-enhanced, multispectral image of Ronne Ice Shelf with a standard band 7 print of the same area. Figure 6 offers an interpretation using data from adjacent images and also shows ice thicknesses from radio echo-sounding. Although much can be inferred from the pattern of ice-thickness isopleths, the visible flowlines reveal more. At the bottom margin, Kershaw Ice Rumples offer a type specimen of a thick ice shelf forcing its way over a shoal. A measured cross-section of this feature (Swithinbank 1977) shows the floating ice shelf progressively thickening to $1100 \mathrm{~m}$ as it approaches the obstruction and then rapidly attenuating to only $600 \mathrm{~m}$ as it slides over the shoal. The disturbance to the flow of the ice shelf can be seen from the satellite image to extend at least $180 \mathrm{~km}$ downstream. The origin of the principal flowlines is readily apparent: they represent sutures recording the confluence of discrete ice streams. Between the major ice streams there are narrow bands (not identified in Fig.6) originating from sources outside the image which contribute lesser amounts of ice: Fowler Peninsula, Fletcher Promontory, glaciers flowing from the Ellsworth Mountains, Skytrain Ice Rise, Hercules Inlet, and the inland ice sheet between Hercules Inlet and Institute Ice Stream. Although initially wide, these flow bands become attenuated by longitudinal extension as they join the major ice streams.

Using a velocity of about $400 \mathrm{~m} \mathrm{a}^{-1}$, as determined by Stephenson and Doake (1982), the downstream extent of visible flow lines on the image implies that, in spite of snow accumulation, the flow lines remain on the surface for hundreds of years. Just what the MSS is responding to remains unclear. A party which traversed the bottom right hand corner of this image in January 1985 was not conscious of any surface topography. By means of optical levelling, however, they were able to demonstrate a $1 \mathrm{~m}$ drop in surface level (spread over $1 \mathrm{~km}$ ) on crossing one of the flow lines visible on the image (personal communication from Andrew Smith).

Although such flow features are believed to show the present direction of ice movement, strictly speaking they record the path along which the ice has moved. Perhaps we should be referring to fossil flow lines. If any tributary glacier should surge, it would be quite possible for the direction of ice movement at that time not to be parallel with the visible flow lines. For essentially the same reason, sinuous medial moraines are a diagnostic feature of surging valley glaciers or of glaciers whose tributaries surge. On Ronne Ice Shelf, however, we see no evidence of surging during the past several hundred years.

The rifts near the top of the image show where one component ice stream has been torn apart by stresses transmitted from neighbouring ice streams; their aperiodicity has not been explained but it suggests non-steady conditions somewhere in the ice shelf system. Note how well shown is the apparently double summit ridge on Korff Ice Rise. The grounding line at every land ice margin of the ice shelf is sharply defined.

The dark patch that looks rather like a photographic processing blemish in the lower left quadrant of Figure 4 appears on other ice shelf images. We believe that either it is a thin layer of drifting snow or alternatively that it is an area of recently deposited snow. If this is so, the MSS may be responding to the lower albedo of new snow which has not had time to recrystallize.

\section{GEODETIC CONTROL}

Figures 1 and 4 both deserve to be published as false-colour image maps at 1:250000. There is already adequate geodetic control in the mountain area to which the Figure 1 image can be geometrically adjusted. Figure 4 presents a different problem. There is not one single rock outcrop in the $34000 \mathrm{~km}^{2}$ area shown. In glaciological terms, however, the features revealed are just as important as those seen in Figure 1; perhaps more so because ice shelf surface features are less conspicuous than ice stream features and many cannot be seen at all in an unenhanced image (Fig.5). Whereas earlier it was thought that mapping control on ice sheets could only be obtained through saturating single pixels by deploying ground-based reflectors 


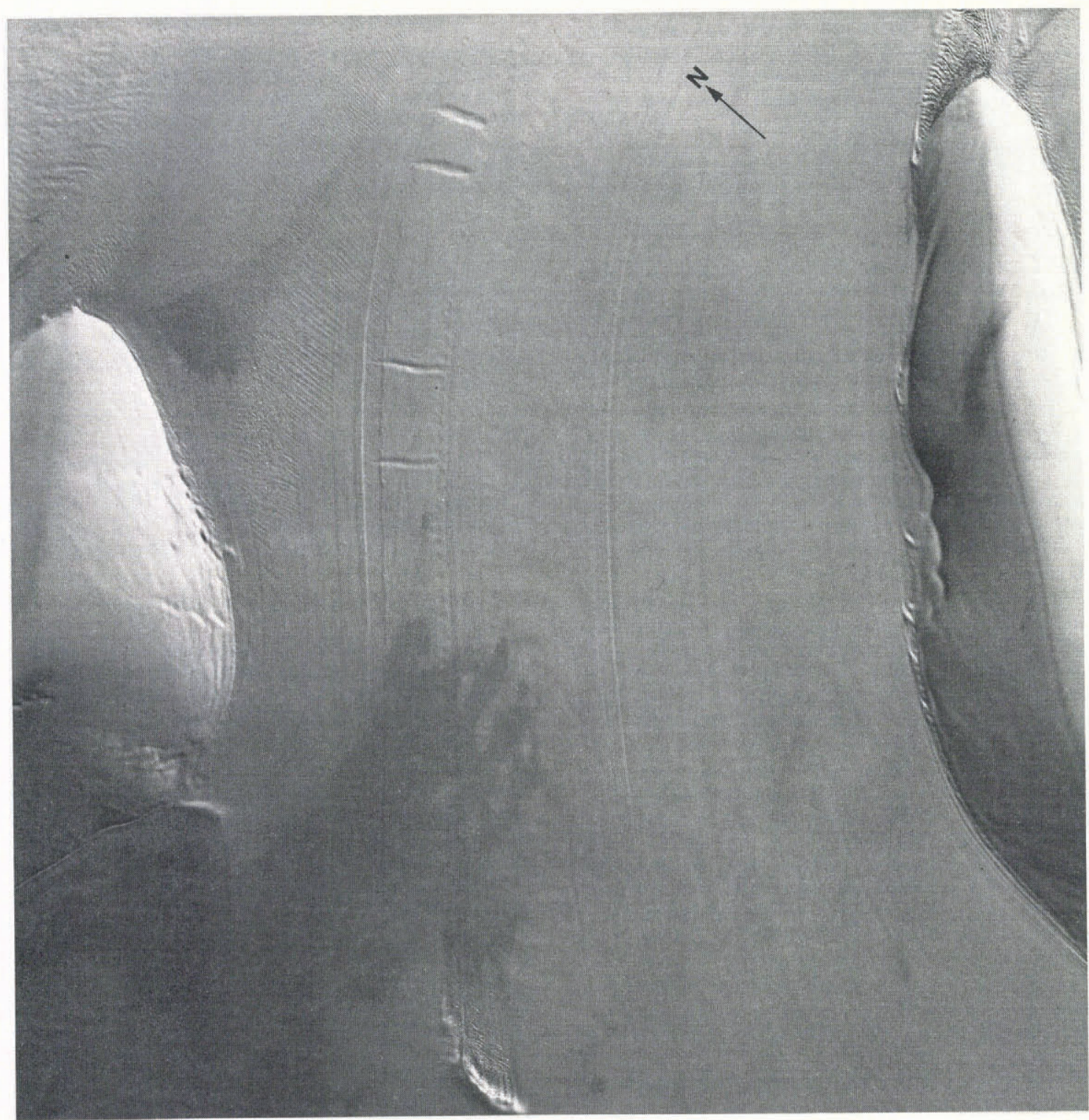

Fig.4. Landsat 1 digitally-enhanced composite image of Fowler Peninsula, Ronne Ice Shelf, and Korff Ice Rise, 13 February 1974 (No. 1570-11031, bands 4, 5 and 7; Path 217, Row 117). NASA image courtesy of Flagstaff (Arizona) Image Processing Facility, US Geological Survey.

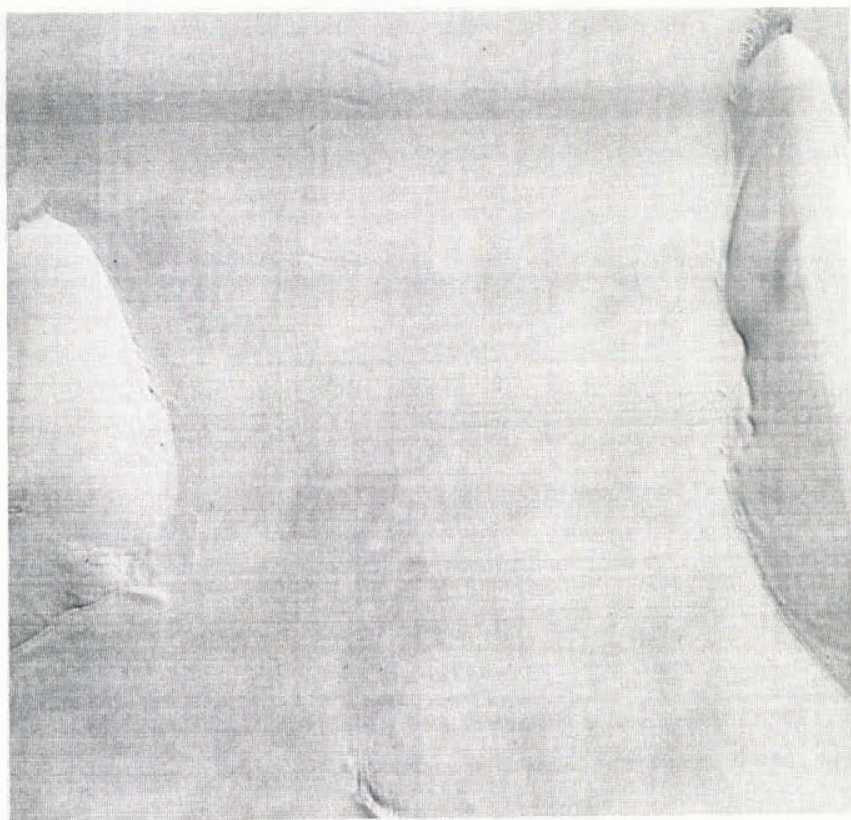

Fig.5. Standard print of the same scene (No. 1570-11031, band 7) without enhancement. From print supplied by EROS Data Center. before a satellite pass, we now know that passing Landsats have not even been recording Antarctic images on ninety nine out of every hundred passes since 1974. We must find a practical and economical way to establish control points for images recorded since 1972 as well as for those to be obtained in the future. Where there are sufficiently well-defined features, such as rifts or the northern point of Korff Ice Rise (Fig.4), Doppler satellite observations can be made at image-identifiable points. Indeed Korff Ice Rise was fixed by this means in the course of a joint British Antarctic Survey/US Geological Survey operation in 1978. Six further sites were occupied on Ronne Ice Shelf and its ice rises. While ice rise features are generally slow-moving, rifts on an ice shelf are moving at the same speed as the ice shelf (sometimes metres per day). In this case, the velocity of the identified feature must be determined by Doppler satellite observations separated by an appropriate interval. The velocity is then applied as a reduction-to-epoch, in order to determine the position of the station at the time the image was recorded. Because of errors inherent in extrapolating ice movement and errors in accurate image-identification of observing sites, the standard of geodetic control can never approach that of conventional surveys based on rock stations. But the precise standards of conventional surveys are unnecessary for ice sheet maps. 


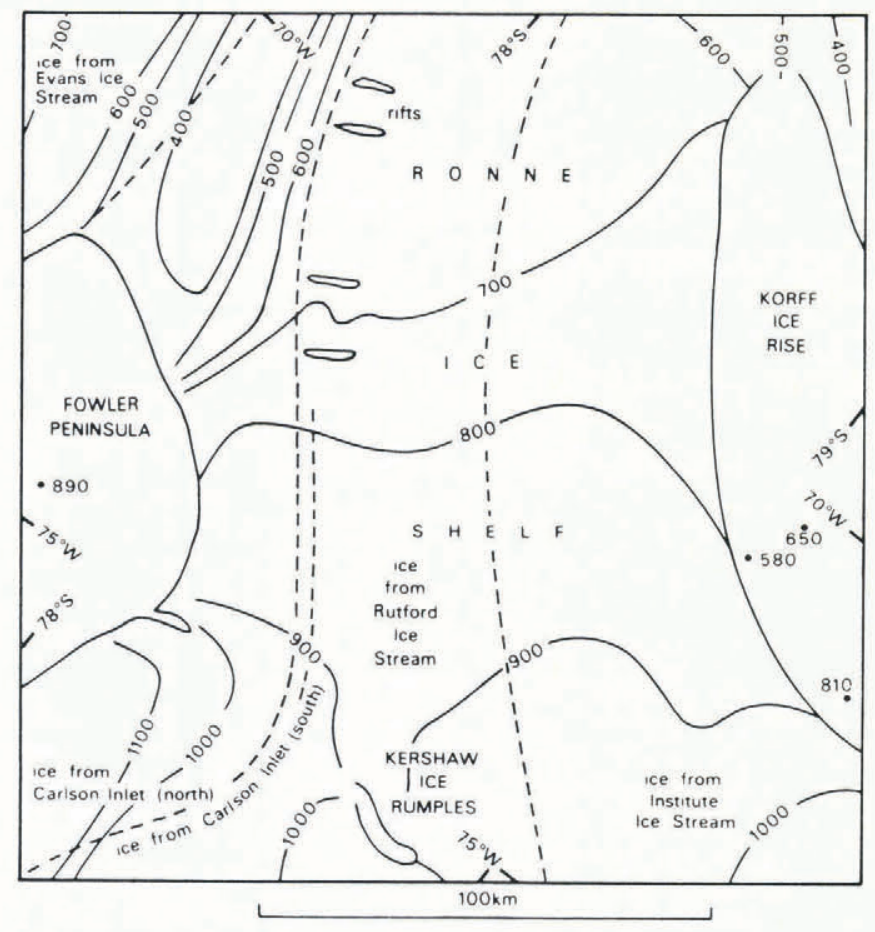

Fig.6. Sketch map of features shown in Fig.4. Spot soundings give ice thickness in metres (on land) and ice thickness isopleths (on ice shelf) from Crabtree and Doake (1986) and British Antarctic Survey (unpublished).

\section{CONCLUSIONS}

Ice sheet maps are needed as much in glaciology as outcrop maps are needed for geology. Landsat multispectral images can be digitally enhanced to show important ice-surface detail. Whereas uncontrolled images contain the same information, a geodetic frame of reference is essential for studies of ice dynamics and for quantifying changes with time. Moreover, the photographic products of Landsat imagery have now become so expensive that only printed image maps can be made available to any substantial number of users. The map scale must be selected according to the need, the resources, and the number of users. At one extreme, a 1:5000 000 image map of the whole of Antarctica has been proposed by the US Geological Survey. At the other extreme, Landsat Thematic Mapper images have been successfully used for land-use mapping in other continents at 1:100 000. However, at its present stage of development, Antarctic glaciology is probably best served by image maps at scales from $1: 250000$ to $1: 1000000$.

\section{REFERENCES}

Crabtree R D, Doake C S M 1986 Radio-echo investigations of Ronne Ice Shelf. Annals of Glaciology 8:

Gunning H C (ed) 1966 Symposium on Glacier Mapping, Ottawa, 1965. Canadian Journal of Earth Sciences 3(6): $737-915$

Lucchitta B K, Eliason E M, Southworth S 1985 Multispectral digital mapping of Antarctica with Landsat images. Antarctic Journal of the United States 19(5), 1984: $249-250$

Martin P J 1976 Ridges on Antarctic ice rises. Journal of Glaciology 17(75): 141-144

Martin P J, Sanderson T J O 1980 Morphology and dynamics of ice rises. Journal of Glaciology 25(91): 33-45 Stephenson S N, Doake C S M 1982 Dynamic behaviour of Rutford Ice Stream. Annals of Glaciology 3: 295-299

Swithinbank C W M 1977 Glaciological research in the Antarctic Peninsula. Philosophical Transactions of the Royal Society of London Ser B 279(963): 161-183 